\title{
Estabilidades de cristal: claves y categorías para caracterizar el trabajo de limpieza no doméstica en Argentina ${ }^{1}$
}

\author{
María Lorena Capogrossi ${ }^{2}$ \\ CIECS-CONICET y UNC \\ (iD) https://orcid.org/0000-0002-8809-1837
}

Resumen: Tomando como caso de estudio a las mujeres que trabajan en empresas de limpieza no doméstica en la ciudad de Córdoba, Argentina, en este artículo definimos algunas categorías teóricas que, por un lado, recuperan las significaciones, sentidos y valoraciones que las operarias dan a sus ocupaciones y, por el otro, contemplan los rasgos principales de este tipo de empleo. Para ello adoptamos una perspectiva metodológica cualitativa, de carácter etnográfico, basada en observaciones de campo, registros y notas y diez entrevistas semiestructuradas realizadas a distintas mujeres empleadas en diferentes empresas del sector. Luego de identificar las tensiones que aparecen entre los sentidos que estas operarias dan a su trabajo y los rasgos precarizantes que las investigadoras observamos dentro de este nicho laboral, proponemos la categoría estabilidades de cristal como recurso teórico que contempla las diferentes dimensiones que reviste este universo laboral. Ese concepto permite, por un lado, incorporar aquellos rasgos que este tipo de ocupaciones presenta, a saber, formalidad contractual pero acompañada de salarios depreciados, horas extraordinarias no pagas, imposibilidad de planificar las vacaciones, limitaciones en el uso de las licencias, penalizaciones, control y maltratos. Por el otro, también posibilita entender por qué estos empleos son opciones preferibles con relación a las trayectorias previas de las mujeres. Lo que se valora del trabajo de limpieza no doméstica es la estabilidad contractual y salarial en comparación con sus empleos anteriores.

Palabras clave: condiciones de trabajo; estabilidades de cristal; género; trabajo de limpieza no doméstica; trayectorias laborales

Recibido: 18/09/2019 | Aceptado: 10/03/2020 | Disponible en línea: 05/06/2020

Como citar este artículo: Capogrossi M. L. (2020). Estabilidades de cristal: claves y categorías para caracterizar el trabajo de limpieza no doméstica en Argentina. Jangwa Pana, 19(3), 390 - 412. Doi: https://doi.org/10.21676/16574923.3517

Abstract: Taking as a case study the women who work in non-domestic cleaning companies in Córdoba, Argentina, in this article we define some theoretical categories that, on the one hand, recover the meanings and assessments that the operators give to their occupations and, on the other hand, they contemplate the main

1 Este artículo es producto de mi proyecto actual de la carrera de Investigación Científica de CONICET, denominado "Los colores de lo invisible: las múltiples dimensiones del trabajo de limpieza no doméstica en Córdoba". También se enmarca en el proyecto financiado por SeCyT-UNC, de la que soy investigadora responsable y que dirige la Dra. María José Magliano, titulado "Lo esencial es invisible a los ojos: género y trabajo de limpieza en Córdoba".

2 Correo electrónico: lcapogrossi@yahoo.com.ar 
features on this type of employment. For this we adopt a qualitative methodological perspective, ethnographic, based on observations fields, records and notes and ten semi-structured interviews conducted with different women employed in different companies in the sector. After identifying the tensions that appear between the senses that these operators give to their work and the precarious features that the researchers we observe within this sector, we propose the category glass stabilities as a theorethical resource that contemplates the different dimensions that has this labor universe. This concept allows, on the one hand, to incorporate those features that this type of occupations presents, for example, contractual formality but accompanied by depreciated wages, overtime not paid, inability to plan vacations, limitations on the use of licenses, penalties, control and mistreatment. On the other hand, it also makes it possible to understand why these jobs are preferable options in relation to the previous trajectories of women. What is valued for non-domestic cleaning work is contractual and salary stability compared to their previous jobs.

Keywords: crystal stabilities; gender; non-domestic cleaning job; work conditions; work trajectories

\section{Introducción}

El objetivo principal de esta investigación en curso es definir algunas categorías teóricas que nos permitan caracterizar, en sus especificidades, el empleo en empresas de limpieza no doméstica en la ciudad de Córdoba, Argentina. Entendemos como trabajo de limpieza no doméstica el que se realiza en relación de dependencia en firmas tercerizadas, las cuales ofrecen una serie de servicios a empresas, organismos públicos y privados, centros de salud y comerciales, bancos, escuelas, etc. Entre las prestaciones que brindan pueden destacarse: la limpieza y el lavado en general, el rasqueteado y plastificado de pisos y mobiliario, la limpieza y lavado de alfombras y cortinas, superficies vidriadas y metálicas, la limpieza de vidrios en altura, la desinfección, la desratización, etc. ${ }^{3}$

Teniendo esto presente, aquí nos proponemos describir cuáles son las condiciones de trabajo que atraviesan este nicho del mercado laboral para comenzar a constituir un corpus de datos significativo que haga posible diseñar un mapa más complejo del sector.

Dirigir nuestra atención hacia las condiciones de empleabilidad y hacia las trayectorias laborales de quienes se desempeñan en el sector nos permite, por un lado, precisar los contornos de una ocupación que no ha sido prioritaria en los estudios sobre el trabajo, ${ }^{4}$ y por

3 La descripción de las tareas que supone el empleo en empresas de limpieza no doméstica se encuentra consignado en la Convención Colectiva de Trabajo N. 392 que rige para este sector (Ministerio de Trabajo, 2004).

4 En Argentina, en los últimos cinco años solo hemos podido identificar los estudios incipientes sobre el sector de Capogrossi (2020; 2018), Gorban y Tizziani (2018) y las ponencias de Tizziani (2017). Estos textos hacen hincapié en las principales características del sector dentro del mercado de trabajo en Argentina. Los textos de Capogrossi se detienen en aquellos rasgos que refieren a la sobreexplotación, pero también en las valoraciones que realizan las mujeres acerca de estas ocupaciones. Los trabajos de Gorban y Tizziani son de carácter más sociológico e indagan en torno de los patrones de segregación multidimensionales de género y sector socioeconómico en el mundo del trabajo para el caso de la ciudad y área metropolitana de Buenos Aires. Para ello analizarán las experiencias de trabajo de las mujeres de sectores populares centrándose en los servicios de limpieza y en las ocupaciones de estética En América Latina, para el mismo período, podemos encontrar los textos de Dresch; Vieira Zanardine y Faux, (2015); Entwistle, (2015); Franco Quiñónez y Santa Cruz Ortiz (2016); Krueguer Oliveira, Pérez Nebra y Antloga (2015). El primero aborda las percepciones de género que tienen las trabajadoras de limpieza dentro de un centro de enseñanza superior y allí observan cómo la división sexual del trabajo se mezcla con las experiencias de las operarias y esto se manifiesta en sus discursos. El trabajo de Entwistle se ocupa de analizar los modos en que las mujeres que trabajan como personal de limpieza urbano de la Empresa Municipal de Servicios de Aseo (EMSA), en Cochabamba, Bolivia, construyen percepciones acerca de sus trayectorias laborales. Allí observa cómo las desigualdades económicas, de género y poder, en su ámbito laboral, así como en los hogares de procedencia, se conjugan en la organización de esas trayectorias. 
el otro, tensionar algunas clasificaciones con relación a lo que nos dicen los datos etnográficos.

Respecto al primer punto, quizá sea enriquecedor pensar que lo acotado del número de producciones que tienen como objeto al trabajo de limpieza no doméstica es resultado de una combinación de factores. Entre ellos, la preeminencia que tiene, en las ciencias sociales, el interés por el trabajo industrial y por las relaciones sociales y sindicales enmarcadas en esos espacios de trabajo, o el énfasis que se ha puesto, en la última década, a los procesos autogestivos o al trabajo enmarcado dentro de la economía popular.

También podríamos incluir como dimensión explicativa la expansión relativamente reciente de las empresas de limpieza no doméstica, que tuvieron su auge a partir de la década de los años noventa cuando los procesos de tercerización -que acompañaron las políticas de ajuste estructural digitadas desde los organismos financieros internacionales- atravesaron las economías latinoamericanas (Battistini, 2018; De la Garza, 2012).

Además de todo esto, consideramos que la invisibilización que mediatiza las experiencias de estas trabajadoras de limpieza también tiñe los espacios académicos y la elección de nudos problemáticos de investigación. Iniciar una trayectoria de indagación sobre el sector pretende subsanar estos silencios y marcar la relevancia que, en los últimos años, han tenido las empresas de limpieza no doméstica como oferentes de trabajo para los sectores más empobrecidos de la población.

Respecto al segundo eje que señalamos al comienzo de esta introducción, poner en discusión las construcciones académicas y las clasificaciones que realizamos acerca de lo que es "estable", "precario" o "informal", permite repensar algunas dimensiones que atraviesan el trabajo, la vida y las representaciones de las y los trabajadores.

Estas reflexiones son posibles porque el trabajo de campo generó una instancia de revisión intensa que nos obligó a definir metodológicamente desde donde posicionarnos como investigadoras. En ese sentido, los estudios pioneros de José Leite Lopes contribuyeron a esclarecer esos recorridos y nos permitieron optar por una estrategia que recupera la palabra de los actores con los que construimos los datos de nuestras pesquisas (Leite Lopes, 2011). Las significaciones que los sujetos dan a sus tareas y a las relaciones y procesos que se construyen y producen en el interior de los espacios de trabajo, son elementos fundamentales para repensar clasificaciones o conceptualizaciones que no contemplan cabalmente las múltiples dimensiones que atraviesan los universos sociales que analizamos. Como sostiene Leite Lopes, nuestro desafío es aplicar el abordaje tradicional de la antropología social a un grupo de operarias de limpieza: “(...) abordaje que se caracterizaría por el punto de partida de su démarche teórica - comenzar por las representaciones de las categorías de pensamiento

Por otro lado, la tesis de Franco Quiñónez, Santa Cruz y Ortiz se pregunta acerca de las percepciones en la salud tanto física como psíquica de las mujeres que trabajan en empresas tercerizadas de Paraguay e identifica sus condiciones laborales. Por último, el artículo de Krueguer Oliveira, Pérez Nebra y Antloga (2015) analiza la rotación de las y los operarios de limpieza y la asocia a ciertas características que tienen estos empleos como la invisibilidad, la poca valoración social y el desprecio. 
y de los modelos de comportamiento del grupo social estudiado (...)” (Leite Lopes, 2011, p. 75).

Situarse aquí supone considerar e incorporar a las investigaciones, los significados que los actores construyen sobre sus prácticas económicas, culturales y sociales. Esto quiere decir que:

(...) la cultura dominada siempre se afirma (...) en la misma relación que domina. Esta afirmación encuentra su lugar en la reinterpretación que los obreros realizan sobre las categorías y prácticas que les son impuestas, incluso en la esfera de la producción. Porque si la fuerza de trabajo posee una funcionalidad esencial para el capital y para su organización de la producción, siendo incluso un aspecto del propio capital - el "capital variable"-, los detentores de esa fuerza de trabajo - los obreros de "carne y hueso"- reinterpretan esa organización de la producción en función de sus intereses, los cuales no dejan de ser contradictorios con los del capital (Leite Lopes, 2011, pp. 76-77).

Cuando hace un año comenzamos a indagar sobre las empresas de limpieza de la ciudad de Córdoba, partimos de dos supuestos que hubo que matizar a medida que avanzábamos en la obtención de datos. Por un lado, suponíamos que existía una prevalencia femenina en el ejercicio de este tipo de tareas y, por el otro, considerábamos que el sector estaba atravesado por condiciones de trabajo y de contratación muy precarias que inducían a pensar en la completa inestabilidad laboral de las mujeres que ingresaban a este segmento del mercado laboral.

Respecto a lo primero, un repaso por la información contenida en la Encuesta Permanente de Hogares (EPH) mostró que el sector estaba lejos de constituirse como un territorio feminizado. De las 28.792 personas que, a comienzos de 2017, se desempeñaban como operarias/os de limpieza en Córdoba, solo 44,4\% eran mujeres (12.802 personas) y el resto varones. ${ }^{5} \mathrm{Si}$ bien durante la realización de las entrevistas aparecen diferenciaciones por género en el ejercicio de algunas tareas y en el acceso a determinadas categorías, en términos de incorporación a este nicho laboral no existen diferencias significativas entre mujeres y varones.

El segundo elemento que se tensionó al realizar el trabajo de campo fue la asociación entre inestabilidad y precariedad. Los datos brindados por las informantes mostraron algunas características del trabajo de limpieza no doméstica como: la contratación irregular, la renovación anual de los contratos, los bajos salarios, la alta rotatividad entre empresas, la flexibilidad laboral, la falta de insumos, el maltrato, entre otros rasgos que ya hemos descrito en algunos artículos previos (Capogrossi, 2019; 2018). Estas dimensiones, evidentes en la totalidad de las entrevistas efectuadas, en un principio nos hicieron asociar irreflexivamente- la precariedad que aparecía en las descripciones, a una situación de permanente inestabilidad e incertidumbre para estas mujeres. Sin embargo, al preguntar acerca de las percepciones sobre su trabajo, la mayoría de las operarias respondió que lo

5 Estos datos se corresponden con los conglomerados de Gran Córdoba y Río Cuarto. Cfr. Encuesta Permanente de Hogares. Primer trimestre de 2017 (www.indec.gob.ar). 
preferían con relación a sus empleos anteriores por la estabilidad que les brindaba. Esto puso de relieve la necesidad de profundizar en las trayectorias laborales previas para comprender las razones por las cuales representaban al trabajo en las empresas de limpieza como un trabajo estable.

Por ello el objetivo de este artículo es revisar algunos rasgos del empleo en empresas de limpieza no doméstica, recuperar los sentidos, significados y valoraciones que las mujeres que trabajan allí dan a sus trabajos y avanzar en el desarrollo de la categoría estabilidades de cristal que nos permitirá dar cuenta de las tensiones que identificamos al realizar el trabajo etnográfico.

\section{Metodología}

Nuestra investigación aborda, como problema de estudio, las características del trabajo de limpieza no doméstica en la ciudad de Córdoba, Argentina. Los principales interrogantes que la atraviesan se estructuran en torno a condiciones de contratación, categorías salariales, dispositivos disciplinares y trayectorias laborales, haciendo hincapié en las representaciones y significados que las personas empleadas en el sector dan a las actividades que realizan.

Metodológicamente adoptamos una estrategia de carácter cualitativo que recupera los aportes teóricos de la antropología del trabajo (Leite Lopes, 2011; Soul, 2015), particularmente la dimensión interdisciplinar y sus diálogos con la historia y la sociología y las preguntas etnográficas con relación a las maneras en que el espacio de trabajo configura sentidos, normas, intereses y valores. Un elemento fundamental que quisiéramos rescatar de este campo disciplinar es la preocupación por dar prioridad a aquello que las y los trabajadores tienen para decir con relación a las tareas que realizan, a los vínculos por los que son atravesadas/os y a las contradicciones a las que se ven sometidos/as. La relevancia que concedimos a este aspecto es lo que nos posibilita dar cuerpo a esta propuesta de reflexión y revisita de las clasificaciones tradicionales que tiene como resultado el esbozo de una categoría que permita pensar multidimensionalmente este tipo de empleo.

Considerando esto último, una de las apuestas teórico/metodológicas asumidas en este artículo se relaciona con dar centralidad a las prácticas, narrativas, valoraciones, experiencias y significados de las personas con las que construimos conocimiento, entendiendo que a cada momento entran en tensión, interactúan y se articulan con condicionamientos estructurales que atraviesan sus recorridos biográficos. De este modo, recuperamos el planteo de Beverly Skeggs cuando sostiene que:

(...) se puede transformar rotundamente la teoría si se permite que otros participen en las discusiones. Las mujeres [y varones] de este estudio no son meras cifras a partir de las cuales las posiciones subjetivas pueden ser descifradas. Antes bien, participan activamente en producir el significado de las posiciones que ocupan (a regañadientes o voluntariamente) o se niegan a ocupar (...) (Skeggs, 2019, p. 25).

La etnografía es una estrategia privilegiada para dar cuenta del entramado complejo que caracteriza a los procesos sociales y a las experiencias de vida, a partir de la construcción de datos derivados del contacto y la cimentación de las relaciones con los actores con quienes 
trabajamos. Como sostiene Grimberg, el trabajo de campo “(...) implica no sólo observar sino también participar de las situaciones de vida y transformar la propia experiencia de investigador en un hecho etnográfico, es decir en un dato construido" (Grimberg, 2009, p. $85)$.

La estrategia etnográfica supuso, entonces, tanto la observación y el registro de campo como la realización de diez entrevistas semi-estructuradas con guías flexibles a mujeres que se desempeñan actualmente en empresas de limpieza no doméstica tercerizadas. Para dimensionar este nicho laboral, nos interesa señalar que en Argentina, para el año 2017, un total de 262.165 mujeres se desempeñaban como operarias de limpieza, según datos registrados por la Encuesta Permanente de Hogares (EPH), con un promedio de edad que varía entre 40 y 42 años. De ese total, 11452 mujeres fueron registradas en los dos principales aglomerados de Córdoba, Capital y Río Cuarto, pero aquí las edades promedio se sitúan entre 35 y 44 años. ${ }^{6}$

El primer ejercicio que hicimos después de la elección del tema fue el recorte del universo de actores con los cuales pretendíamos construir nuestra pesquisa. Para ello fue fundamental la lectura de la Convención Colectiva de Trabajo 392, homologada entre el Sindicato de Obreros y Empleados de Empresas de Limpieza, Servicios y Afines de Córdoba (S.O.E.L.S.A.C.) y la Cámara Cordobesa de Empresas de Servicios Generales. En ella se establecía una delimitación de categorías que nos permitió definir a las operarias sin calificación como las interlocutoras principales que nos permitirían constituir, de manera acabada, el mapa más completo de este fragmento del mercado laboral.

A partir de entonces comenzamos a contactarnos con las primeras informantes que trazaron las pinceladas iniciales del trabajo de limpieza no doméstica. Un dato etnográfico relevante fue la facilidad para acceder a conversar con operarias que se desempeñaban en estas empresas, porque toda persona con algún tipo de vínculo con nosotras conocía a alguien que trabajaba en el sector. Creemos que esto es un indicador significativo de la presencia de estas trabajadoras y trabajadores en una multiplicidad de espacios: universidades, escuelas, hospitales, centros comerciales, organismos públicos, bancos, etc.

En la etapa de abordaje preliminar nos acercamos a algunas mujeres y tuvimos conversaciones informales, prescindiendo de guías establecidas previamente. Sin embargo, esta fase permitió caracterizar de manera general al sector en el cual desempeñan sus tareas y diagramar algunos nudos problemáticos por desarrollar a lo largo de la investigación. Esos

\footnotetext{
6 Existe un desfasaje en el número de trabajadores y trabajadoras contemplado por la Convención Colectiva de Trabajo y el proporcionado en la Encuesta Permanente de Hogares (EPH) para el sector. El primero, estima que para el año 2004 son 4.000 las personas empleadas en empresas de limpieza privadas en Córdoba; mientras que la EPH registra un total de 18.674 operarias y operarios en el mismo año. Quizás esta diferencia de datos se explique porque la EPH no diferencia entre empleo registrado y no registrado, dimensionando, de esta manera, la falta de regulación que existe en este sector. Cfr. Encuesta Permanente de Hogares, tercer trimestre de 2017 (www.indec.gob.ar).
} 
acercamientos se produjeron y se producen, en la mayoría de los casos, en sus lugares de trabajo o en manifestaciones callejeras de las que participa el sindicato que las representa. ${ }^{7}$

Después de establecidos los contactos iniciales con las mujeres y de bosquejar las principales hipótesis de trabajo, comenzó la realización de entrevistas semiestructuradas individuales, a partir de una guía de preguntas preestablecida. De ellas obtuvimos datos sobre las actividades que realizan para las empresas tercerizadas, comprendimos los significados y representaciones que las mujeres otorgan a su trabajo, se esclarecieron dudas acerca de los contratos y las escalas salariales, se describieron las relaciones que tienen lugar en estos espacios, etc. Es necesario destacar que el corpus de preguntas es flexible y posibilita cierta ductilidad para redefinir la orientación de la entrevista en función de la aparición de elementos imprevistos que puedan surgir durante el trabajo de campo (Peirano, 2004, p. 22). En el diseño de las entrevistas individuales se incorporaron aspectos de la técnica de historias de vida; para la dimensión que queremos trabajar aquí, la utilización de ésta última fue necesaria para reconstruir determinadas trayectorias que contemplaron recorridos individuales y familiares, laborales, educativos y permitieron descubrir fragmentos de las experiencias que posibilitaron pensar en la idea de estabilidad que tienen las personas que se desempeñan en el sector. Hasta el momento se hicieron diez entrevistas a varones y mujeres de diferentes empresas de la ciudad de Córdoba.

Luego de que las entrevistas fueran digitalizadas, se les entregó una copia a las entrevistadas para que pudieran leerla y agregar o quitar fragmentos. Un acuerdo al que llegamos es omitir sus nombres y las filiaciones de las empresas para las que trabajan, a fin de proteger sus identidades. De esta manera, cuando sean citadas, en todos los casos se utilizarán iniciales ficticias.

La estrategia etnográfica que elegimos incluyó también la observación y el registro de lo que ocurre en el campo a través de diferentes técnicas: reportes, informes y notas. En algunos lugares pudimos tomar fotografías que nos proporcionaron algunas pistas que enriquecieron enormemente la reflexión.

La información recabada en las entrevistas se complementa con documentación sindical e información estadística recabada de la Encuesta Permanente de Hogares (EPH), que hace el Instituto de Estadísticas y Censos del Estado Argentino.

Las entrevistas nos han proporcionado datos de diverso tipo que permiten problematizar una gran cantidad de dimensiones sobre el sector. Pero, por una cuestión de extensión, en este artículo solo vamos a detenernos en una escueta descripción de las principales características de las condiciones de trabajo dentro de los empleos de limpieza no doméstica y en las trayectorias laborales de las operarias entrevistadas, porque ello nos posibilitará proponer una serie de elementos que darán cuerpo a la categoría estabilidades frágiles o estabilidades de cristal.

\footnotetext{
7 Creemos que la posibilidad de realizar las entrevistas en sus lugares de trabajo tiene relación con que los facilitadores del contacto con las trabajadoras, en su mayor parte conocidos de las investigadoras, habilitaron esa posibilidad, favoreciendo encuentros en momentos en que las jefas y jefes estaban ausentes.
} 
Por último, quisiéramos señalar que para revisar una serie de aspectos que cruzan transversalmente nuestro problema de investigación, resultan de central importancia los aportes de la economía feminista pues posibilitan comprender que el mercado laboral no es una entidad sexualmente neutra y que las relaciones de género también atraviesan la organización del trabajo y de la producción (Pérez Orozco, 2014; Carrasco, 1999). Esa dimensión es una variable ineludible para comprender las lógicas del sector que estamos analizando, en tanto se constituye como una de las opciones laborales de las mujeres de bajos ingresos en Argentina (Gorban y Tizziani, 2018).

\section{La precariedad dentro de la estabilidad: condiciones de trabajo en el sector de la limpieza no doméstica}

La multiplicación de empresas dedicadas a la limpieza de oficinas, instituciones públicas y privadas, centros comerciales, bancos, etc. inició su curva ascendente durante la década de 1990 cuando se produce un movimiento masivo de tercerización de servicios y tareas en diferentes establecimientos. Estos procesos de subcontratación fueron resultado de la aplicación de programas de ajuste estructural en los países de América Latina que condujeron a distintas instituciones y empresas, de gestión pública y privada, a buscar mecanismos de reducción de costos. La tercerización o el outsourcing implicó la delegación de una tarea o una actividad en un tercero, lo cual permitió achicar áreas y reducir el gasto en personal e insumos (Battistini, 2018; De la Garza, 2012).

Según la Cámara Argentina de Comercio, en el período 1996-2013 el sector servicios creció $103 \%$ respecto a otros rubros, ubicándose como el primer empleador del país, registrando 65\% del empleo total del sector privado (Cámara Argentina de Comercio, 2013).

Dentro del rubro de limpieza no doméstica, esa expansión tuvo su correlato en el incremento del número de trabajadoras y trabajadores que engrosaron las filas de estas empresas a lo largo de las dos últimas décadas. Si tomamos los datos proporcionados por la Encuesta Permanente de Hogares (EPH) sin desagregar categorías ocupacionales, veremos que para el año 2017 la cantidad de personas que efectuaban tareas de limpieza no doméstica ascendía a 512.660 en Argentina. De ellas, alrededor de 96\% están registradas como trabajadores/as en relación de dependencia.

Un dato relevante que encontramos al comienzo de estas indagaciones fue la paridad existente en la proporción de hombres y mujeres contratadas para este tipo de tareas. Esta dimensión es fundamental porque, antes de entrar al campo, suponíamos que se repetían algunas características del trabajo doméstico remunerado, entre ellas la feminización de la actividad. Sin embargo, el acceso a determinadas fuentes estadísticas nos obligó a redefinir las hipótesis porque las diferencias por género en la categoría operario/a no resultan significativas en el total de las provincias relevadas por la EPH. De este modo, podemos señalar que para el año 2017 unas 262.165 mujeres y unos 207.871 varones se desempeñan como operarias/os de limpieza en Argentina, con un promedio de edad que oscila entre $40 \mathrm{y}$ 42 años. De ese total, 12.802 mujeres y 15.990 varones fueron registrados en los dos principales aglomerados de la ciudad de Córdoba, Capital y Río Cuarto. ${ }^{8}$

8 Todos estos datos fueron extraídos de la Encuesta Permanente de Hogares, tercer trimestre de 2017 (www.indec.gob.ar). 
Las disparidades de género sí son observables entre quienes ocupan las categorías más altas dentro del sector. Los datos de la EPH muestran que para el año 2017, en Córdoba, 2.062 varones se desempeñaban como jefes o supervisores en el rubro de limpieza no doméstica, frente a 725 mujeres. Los varones triplican a las mujeres en estas categorías ocupacionales mostrando que existen territorios "feminizados" y "masculinizados" en los procesos de división y organización del trabajo (Gorban y Tizziani, 2018; Tizziani, 2017). Como sostiene Goren (2017):

las diferencias entre mujeres y varones respecto a las libertades de las que gozan en las distintas sociedades se expresan en la asignación de identidades y actividades, al igual que en la separación de ámbitos de acción para individuos de diferentes sexos que se valorizan en forma diferente, lo que da lugar a un acceso desigual al poder y a los recursos, por un lado, y a la jerarquización de las relaciones entre lo femenino y lo masculino, por el otro [...] (p. 3).

Centrándonos en las características del trabajo de las operarias a quienes entrevistamos, podemos señalar que la Convención Colectiva de Trabajo 392 contempla la realización de una enorme diversidad de actividades bajo el rubro limpieza no doméstica:

(...) limpieza o lavado en general; rasqueteado, aspirado, encerado, lustrado, pulido y plastificado de pisos y mobiliarios. Limpieza en general o lavado de ámbitos alfombrados y cortinados, superficies vidriadas y metálicas. Limpieza y mantenimiento de piletas de natación. Limpieza de vidrios en altura y pisos en general. Limpieza y mantenimiento de carteles interiores y exteriores en altura. Desinfección, desratización, desinsectización y fumigación en general. ${ }^{9}$

Esa heterogeneidad de tareas se mediatiza cuando hacemos las entrevistas y las trabajadoras señalan cómo es un día de trabajo. En estos empleos, en general, las mujeres se encargan del barrido, limpieza de pisos y azulejos, limpieza de baños, lustrado, etc. y no realizan aquellas tareas que requieren fuerza o utilización de algún tipo de maquinaria. Como sosteníamos en otro trabajo, las operarias hacen aquello que supone una "externalización" de las actividades del hogar y los operarios tienen a su cargo lo que implica el uso de fuerza, algún tipo de manipulación de instrumentos o maquinarias o ciertas habilidades "técnico-profesionales", como la limpieza de vidrios en altura (Capogrossi, 2018).

E: Y contame, cómo es un día de trabajo. Un día de trabajo acá y un día de trabajo en $\mathrm{X}$.

F: Acá llegás y lo primero que vas a hacer es el baño porque acá son dos veces a la semana y viste que el baño es como que primordial. El baño, después está el patio, que te fijás más o menos donde están los guardias, cómo está el servicio de ellos. Entonces, si está muy sucio se lo limpia y, si no, le hacés una repasadita y ya está. Y bueno, y después subís a las oficinas y entonces, si, acá ya limpiás. Bueno, acá ya se limpia todo

9 Ministerio de Trabajo de la República Argentina. Convención Colectiva de Trabajo 392. 2 de noviembre de 2004. 
con mucho cuidado porque tienen muchos papeles, tienen muchas computadoras. Entonces, no vaya a ser que toqués algo y le borres todo (...)

Y después, allá en $\mathrm{X}$, bueno, ya cuando entrás a $\mathrm{X}$ uno empieza a ver los servicios que van dejando del turno mañana y, medianamente, decís "me toca acá o allá. Ahí está hecho una mugre, seguramente me va a tocar ahí". Y bueno, empezás. Y el encargado es mucho menor que nosotras, creo que tiene 23 años, R., una mala onda bárbara, o sea, siempre quiere tener la última palabra, no podés discutirle nada porque se pone en el papel de malo. Y bueno, entrás, preparás tus materiales, si hacen falta guantes le pedís. Hay veces que él no tiene guantes y no te da, o sea, tenés que comprarte vos y si no, te arreglás. Y bueno, él te dice [a dónde ir]. Yo, por lo general, voy a la plataforma. Bueno, tenés que (...) limpiar los bancos, sacar todos los papeles, los tachos de basura y siempre hay uno de plataforma que se encarga de los contenedores. Bueno, al contenedor va toda la basura de X. Entonces, por ahí, es feo, más ahora en el verano porque hay veces que no tenés guantes y lo mismo tenés que sacar, vaciar los contenedores para que cuando vayan trayendo basura estén medianamente vacíos. Y tienen que estar ordenados y limpios los contenedores. Y bueno, y ahí renegás porque hay mucha gente que está en situación de calle y va y busca comida ahí y tira toda la basura y tenés que levantarla... Los olores, por ahí los usan de baño... (Entrevista a F, operaria de empresa de limpieza, se desempeña en el rubro transporte y en una dependencia pública, 44 años. Córdoba, 2018).

Bueno, acá entrás a las ocho y, bueno, te ponés a limpiar la playa de estacionamiento, te ponés a limpiar los baños, eh, te ponés a limpiar los vidrios, porque yo los limpio a los vidrios (...) no en altura porque de eso se encarga un compañero de allá, de X. Te ponés a limpiar a donde está la policía, eh... Bueno, los baños, estar pendiente de... Entrás a las celdas, las celdas que están... que te llevan mucho tiempo también...

En D es... el trabajo es más difícil, por ejemplo. Ahí en D, por ejemplo, yo tenía el área de consultorios (...) en el segundo piso. Bueno, yo tenía la parte de ginecología. Yo hacía los dieciocho consultorios, los baños de médicos que están ahí cerca, los baños públicos, donde están los médicos, digo, los pacientes y turnero. Todo eso yo lo tenía que hacer en cuatro horas. Que, bueno, al principio me costaba mucho (...) (Entrevista a $\mathrm{P}$, operaria de empresa de limpieza, se desempeña en una institución privada de servicios y en una institución del rubro salud, 28 años, Córdoba, 2018).

La diversidad de tareas que realizan los y las trabajadores/as de empresas de limpieza no doméstica, sumada a la rotación entre dos o más lugares de trabajo son características que nos van a señalar algunas formas que adquiere la precariedad en estos empleos, precariedad entendida como una relación de desigualdad y jerarquización que se manifiesta política, social y jurídicamente y que se constituye históricamente con la expansión neoliberal (Lorey, 2016, pp. 27-28).

La inexistencia de regulaciones desde el Estado sobre el empleo en el sector es lo que facilita el desarrollo de condiciones laborales donde la sobrecarga de tareas, la falta de elementos de seguridad, la rotación continua, los bajos salarios y el maltrato son generalizados. 
Hay dos dimensiones que aquí quisiéramos señalar porque aparecen en todos los relatos. Por un lado, las formas de contratación y, por el otro, dos tipos de circulación de las trabajadoras: una circulación externa, es decir, entre distintas empresas, y una circulación interna que tiene dos modalidades y que se produce dentro de la misma compañía que las contrata. Nos interesa detenernos en ambos aspectos porque señalan rasgos específicos de estas formas de empleo que nos hacen reflexionar acerca de la existencia de formas de precariedad dentro de la formalidad (Capogrossi, 2019).

Durante la realización de las entrevistas, la pregunta respecto a la contratación nos generó algunas dificultades porque las operarias respondían que se encontraban vinculadas a las empresas con modalidades de "contrato abierto", figura que no existe dentro de la legislación laboral argentina (Ley 20744, 1974/1976). Cuando preguntamos por su significado, nuestras informantes nos contestaron que las hacían firmar un contrato y "(...) papeles en blanco, cuatro o cinco papeles que (...) son futuras suspensiones, futuras sanciones” (Entrevista a M, operaria de empresa de limpieza, se desempeña en un organismo público, 46 años). Las irregularidades identificadas en la instancia de acceso al empleo son las que posteriormente dan lugar a que las y los empleadores puedan modificar unilateralmente las cláusulas bajo las cuales se desarrolla la relación laboral y disciplinen a sus trabajadoras desde el inicio de la relación contractual. Esas hojas en blanco -que todas las operarias saben para qué se utilizarán- son el instrumento de control que habilita otras formas de explotación. Son la "gramática secreta", parafraseando a Levi Strauss, sobre la que se organiza la dimensión simbólica disciplinar en estos espacios (Levi Strauss, 1988, pp. 11-12). Son el "panóptico" moderno de estas formas de empleo que prosperaron con la expansión de los procesos de subcontratación y que señalan las maneras en que se disciplina al trabajo durante esta fase del capitalismo global. Esas hojas, que no dicen nada, pero están presentes en el recuerdo de todas las operarias, entran en el universo de representaciones que las empresas ponen en juego y cuyo poder radica en que la materialización de una suspensión o una sanción se traduce en una reducción considerable de los ingresos o en un posible despido.

Esta característica no es la única que permite definir el mapa del empleo de limpieza no doméstica. También aparecen, como señalamos anteriormente, formas de circulación de las y los trabajadores que dimensionan la precariedad. Una de esas formas de circulación es externa y supone el paso de las operarias por dos, tres o más empresas de limpieza en pocos años. En las entrevistas, las razones para el cambio de empleo expresan que puede ocurrir por despido, por la necesidad de encontrar un lugar de trabajo donde las condiciones sean más favorables o donde no exista maltrato de supervisores o supervisoras.

Y... hace cinco años entré en X. Estuve dos años, dos años estuve ahí en X. Sí, dos años. No, hace seis años y estuve tres años ahí. Y en $\mathrm{Z}$ estuve un par de meses (...) Bueno, y en X era muy malo el trato, en cuanto a calidad humana. Y en la otra, no había maltrato ni nada por el estilo, pero, por ejemplo, yo salí de ahí porque me esguincé el tobillo. Yendo a trabajar me resbalé, antes de subir al colectivo. Y bueno, me volví a mi casa, la ART me cubrió todo porque es un accidente en horario de trabajo y me dieron diez días. (...) Y cuando me tocaba volver a trabajar (...) llamé para avisar que me reintegraba y me dijeron que no fuera al lugar de trabajo, que fuera directamente a la oficina. Y cuando fui a las oficinas al otro día, tenía que firmar la suspensión de diez días. Entonces era como que... si yo le decía "Es un accidente de trabajo, no es que yo 
saqué una carpeta". Y no, me dijeron que lo firmara o no cobraba. Entonces, no, mi marido me estaba esperando afuera y me dice "No, ¿para qué la firmaste?” "Es que, si no la firmaba, no me pagaban”. Me dice: "Pero ¿cuántos días van a cobrar si estuviste diez días de carpeta, más diez de suspensión?", me dice "No vas a cobrar nada". Entonces me preguntó mi marido si tenía currículum. "Bueno, vamos, te llevo ahora", me dice. Él estaba de vacaciones. Y empecé a repartir currículums. Fue un día viernes, y a los cuatro días, el día martes me llamaron de esta empresa (...). Y me llamaron de dos empresas más. Y empecé... un 19 de enero empecé a trabajar (Entrevista a G, operaria de empresa de limpieza, se desempeña en oficinas de organismos públicos y en oficinas privadas, 47 años, Córdoba, 2018).

Como sosteníamos en párrafos anteriores, la inexistencia de mecanismos de control público sobre estas empresas es lo que permite que prosperen todo tipo de irregularidades y abusos cometidos contra las trabajadoras. En ese sentido, pueden identificarse algunas similitudes con las características del trabajo doméstico remunerado (Magliano, 2017; Mallimaci y Magliano, 2016, p. 90).

En el sector también pudimos observar formas de circulación interna. En este caso, estamos haciendo referencia a la rotación entre diferentes "servicios" 10 brindados por una misma empresa que puede obedecer a diferentes causas: para complementar la totalidad de horas diarias o semanales que se exige a las operarias; para cubrir ausencias o licencias de compañeras/os en otros "servicios" o como forma de disciplinamiento.

Los dos primeros ejemplos suponen innumerables problemas para las mujeres, ya que cambiar de lugar de trabajo durante el día o durante la semana supone reorganizar sus vidas con relación a estos traslados. No debemos olvidar que la mayor parte de las operarias, además del trabajo en la empresa de limpieza, tiene a su cargo la realización del trabajo doméstico y las tareas de cuidado en el hogar. Los cambios de un "servicio" a otro, que en ocasiones se hacen en el mismo día, y cuyos gastos corren por cuenta de las trabajadoras, suponen movilizarse de un punto a otro de la ciudad, con sistemas de transporte deficientes y sin posibilidades de negarse a ello. A esto hay que sumarle la adaptación a las nuevas instituciones y a las relaciones con los integrantes de las mismas.

E: O sea, L., que vos terminás tu trabajo en la escuela y si te llaman ¿tenés que ir a otro lugar? ¿O suspendés los trabajos en la escuela y vas a otro lugar a trabajar? ¿Cómo es eso?

L: Y, por ahí te llaman en el horario en que yo estoy trabajando y te dicen: "Andá a tal lugar y quedate hasta que cumplas tu horario". (...) por ahí me saben sacar a las 11, me voy a otra escuela y ahí me quedo hasta las tres. O por ahí cuando necesitan después de las tres, te llaman y te dicen “¿Podés cubrirme el servicio tal, que no fue la operaria?” Y te tenés que quedar a cubrir el otro (...) hasta las tres de la tarde, que cierra el colegio, del otro lugar. Si (...) te llaman para otro lugar y te podés quedar después de hora o te

10 La palabra "servicio" es una categoría nativa. Las mujeres la utilizan para hacer referencia a las tareas desempeñadas en un lugar determinado. Cuando cambian de lugar de trabajo, cambian de "servicio". 
llaman en el horario tuyo, te tienen de un lado a otro. (Entrevista a L, operaria de limpieza, se desempeña en escuelas, 36 años, Córdoba, 2018).

E: Y me contaban algunas mujeres que a veces las cambian de lugar de trabajo si falta alguien en algún otro lado. Y las llaman y se tienen que ir. No sé si en tu caso ocurre lo mismo.

F: Por lo general siempre a los chicos nuevos. Los que ingresan nuevitos, nuevitos, les dicen: "Bueno, vos tenés que prestar servicios en T o en el Hospital X. Entonces van los chicos. Y nunca tenés que decir que no, porque vos le decís que no cuando te toca y [cuando] se les cumplen los tres meses a los chicos, el encargado ve eso y "Bueno, este me dijo que no, no queda". Por más que sea un excelente trabajador. Ha pasado muchas veces ahí en la X. A mí... bueno, antes la supervisora me decía que tenía que ir a cubrir vacaciones a un banco. A mí no me molesta porque yo tengo mis hijos grandes, pero si por ahí las pone en situaciones malas a las que tienen los chicos chiquitos y tienen que modificar todo, que cómo pueden hacer para el colegio o para que no estén solos los hijos. (Entrevista a F., operaria de empresa de limpieza, se desempeña en el rubro transporte y en una dependencia pública, 44 años. Córdoba, 2018).

Estos fragmentos de entrevista permiten dimensionar lo que ocurre durante el proceso de trabajo, cuando las trabajadoras son obligadas a trasladarse de un lugar a otro durante sus jornadas diarias o semanales. Y también posibilitan analizar las repercusiones que las condiciones de trabajo tienen sobre los espacios de reproducción de las operarias. Esto no es un detalle que deba pasarse por alto, pues supone enormes tensiones entre las exigencias de este tipo de empleo en relación de dependencia y las demandas que supone la esfera doméstica para estas mujeres.

Las conversaciones con nuestras informantes fueron esclarecedoras porque permitieron descubrir un tipo de circulación que persigue el disciplinamiento de las trabajadoras. En ocasiones, las suspensiones o las sanciones no son los procedimientos elegidos para castigar el mal desempeño o la rebeldía de las operarias de limpieza, sino que el traslado hacia determinados lugares tiene esa función. En general, se las traslada a lugares donde el trabajo es pesado y excesivo o insalubre, por ejemplo: terminales de autobuses, hospitales, morgues o tribunales de justicia. Negarse a ir a desempeñar estos "servicios" puede terminar en suspensiones:

(...) yo la primera vez que empecé a trabajar en la empresa me mandaron a cubrir, me acuerdo, una navidad, al hospital $\mathrm{X}$ y me quisieron hacer limpiar la morgue y yo no quise ir. Entonces, no fui a trabajar, no me presenté a trabajar y me llamaron y me dijeron que me tenía que presentar sí o sí (...) porque si no iba a hacer como abandono de trabajo y me iban a echar. Entonces, cuando llegué tenía una suspensión y la suspensión era de dos días, y me querían suspender sábado y domingo. (Entrevista a L, operaria de limpieza, se desempeña en escuelas, 36 años, Córdoba, 2018). 


\section{Las estabilidades de cristal}

Entre los elementos que consideramos durante el diseño y la realización de las entrevistas, las trayectorias laborales tuvieron un papel relevante. Nos interesaba, en la fase exploratoria de la investigación, tener un registro retrospectivo de aquellos trabajos por los cuales hubiesen transitado estas mujeres. Esto nos permitiría trazar un mapa de sus recorridos laborales y observar cuáles habían sido sus principales opciones dentro del mercado laboral antes de entrar en relación de dependencia con las empresas de limpieza tercerizadas. ${ }^{11}$

En todos los encuentros que tuvimos con nuestras informantes el trabajo doméstico remunerado apreció como un empleo previo o como complemento del trabajo actual. Además, se sumaban experiencias como ayudantes de peluquería y farmacia, como empleadas de pequeños locales comerciales o como cuidadoras de personas ancianas o enfermas. Las características principales de esas trayectorias precedentes son la informalidad, la ocupación en empleos no registrados o en emprendimientos o negocios familiares y la inexistencia de derechos laborales básicos como vacaciones pagas, licencias por enfermedad o maternidad, sueldo anual complementario, etc.

Esta información nos resultó de vital importancia para poder reflexionar y problematizar algunos aspectos que nos posibilitaran dar cuenta de las valoraciones que las mujeres conferían al trabajo de limpieza no doméstica. De esta manera, se tornó fundamental recuperar categorías nativas o categorías sociales que hicieran referencia a los significados y diferenciaciones que ellas otorgan a las cosas, sentidos derivados de sus propias experiencias y que, en ocasiones, resultan ajenas a los/las investigadores/as (Rockwell, 2009, p. 80). Recuperarlas contribuye a que repensemos nuestras formas de analizar la realidad, incorporando las dimensiones que las operarias encuentran para definir su vida y su trabajo. Esto último supone un desafío metodológico que implica construir reflexiones académicas que incorporen los aportes de las personas con las que dialogamos al realizar etnografías. Con esto queremos decir, siguiendo a Skeggs, que se puede "(...) transformar rotundamente la teoría si se permite que otros participen en las discusiones. Las mujeres de este estudio no son meras cifras a partir de las cuales las posiciones subjetivas pueden ser descifradas. Antes bien, participan activamente en producir el significado de las posiciones que ocupan (...) o se niegan a ocupar" (Skeggs, 2019, p. 24).

De este modo, nuestra apuesta en este texto es poner en tensión aquello que nos haría clasificar estos trabajos como inciertos e inestables debido a las características que tienen y esforzarnos en recrear una categoría que dé cuenta de las valoraciones que las mujeres empleadas en las empresas de limpieza dan a su trabajo. El reto es incorporar esos sentidos sin dejar de contemplar los principales rasgos de estas ocupaciones: bajos salarios, formas de contratación irregulares, circulación continua -interna y externa- invisibilización, escaso reconocimiento, maltrato, etc.

El riesgo de hacer hincapié en una descripción cruda, esto es, sin incorporar las dimensiones subjetivas que nuestras informantes construyen sobre sus puestos de trabajo, es contemplar al sector de limpieza no doméstica solo como un vórtice de precariedad, entendida como

11 Para tener una perspectiva acerca de algunas dimensiones teóricas y metodológicas sobre trayectorias laborales se pueden consultar los trabajos de Longo (2011) y Muñiz Terra, Roberti, Deleo y Hasicic (2013). 
condición laboral cuyos estándares de medición (estabilidad, salario, beneficios sociales, etc.) se encuentran por debajo de la media (Basualdo y Esponda, 2014; Palomino, 2003). Pero eso no estaría reflejando cabalmente el cuadro completo porque entre las mujeres operarias -al contrario de lo que las investigadoras pensábamos- primaba la idea de estabilidad en el puesto y en el salario como principales beneficios obtenidos al ingresar en las empresas tercerizadas. Y esta ponderación se hace cuando consideran sus trayectorias previas y es la que determina que nuestras informantes elijan estos empleos por sobre otros:

E: Me estabas diciendo por qué seguís en la empresa y no en casa de familia (...)

F: Primero por la plata. Para mí es como mi segunda casa, porque estás todo el día. En casa de familia ahora es como que está medio difícil. Hay muchos extranjeros que trabajan por menos que los argentinos. Entonces hay veces que abusan y quieren pagarte lo que ellos quieren. (Entrevista a F, operaria de limpieza, se desempeña en el rubro transporte y en una dependencia pública, 44 años. Córdoba, 2018).

E: Y vos me decías que antes trabajabas en casa de familia... comparando ese trabajo con el de ahora ¿cuál te parece mejor? ¿Por qué te parece mejor (...)?

L: Ahora, donde estoy, por la tranquilidad (...) Por la paga me conviene más acá ¿no es cierto? Bah, creo, porque tengo un sueldo (...) limpiar en una casa de familia también te tratan mal. No es buena la atención, a no ser que sea un amigo. (...) yo trabajé en una peluquería y, a su vez, era amigo mío, y entonces charlábamos y me trataba re bien. Yo manejaba la caja. Pero en otras casas que he trabajado, no. No, porque vos sos la sirvienta y en esos lugares te tratan mal. (Entrevista a L, operaria de limpieza, se desempeña en escuelas, 36 años, Córdoba, 2018).

Me gusta trabajar y para mí el trabajo es como un cable a tierra... Tener trabajo a mí me dignifica como persona. Entonces, no le veo la parte fea. Salvo cuando hay un maltrato hacia mi persona. (Entrevista a G, operaria de empresa de limpieza, se desempeña en oficinas de organismos públicos y en oficinas privadas, 46 años, Córdoba, 2018).

¿Cómo lograr entonces la mixtura de todos estos aspectos que, a primera vista, se mostraban contradictorios? ¿Cómo incorporar esos sentidos y valoraciones nativas y, al mismo tiempo, dar cuenta de las condiciones laborales desfavorables que atraviesan el trabajo de limpieza no doméstica?

La manera que encontramos de resolver estas tensiones fue la creación de un concepto que reuniera esas dimensiones aparentemente discrepantes. De ese ejercicio reflexivo surgió la categoría estabilidades de cristal que reúne tanto las significaciones que las entrevistadas otorgan al trabajo que realizan, como la precariedad que atraviesa el universo laboral de la limpieza no doméstica.

Quizás uno de los elementos por considerar sea el proceso de ajuste estructural que vivió Argentina durante los años noventa y que catapultó hacia el desempleo a $20 \%$ aproximadamente de la Población Económicamente Activa (PEA) en el período que se extiende entre 1994 y 2002 (Palomino, 2003). Podríamos aventurar que esos acontecimientos marcaron las experiencias de un gran porcentaje de los habitantes del país, lo cual se tradujo 
y se traduce en la consolidación de una subjetividad donde el miedo a la desocupación atraviesa las vivencias de gran parte de la población. Nos parece adecuado tenerla presente como dimensión que coadyuva a comprender la valoración del trabajo de limpieza no doméstica por su estabilidad, aun cuando las condiciones laborales sean desfavorables. ${ }^{12}$

Las descripciones acerca de la tranquilidad o estabilidad que entraña tener un contrato "en blanco", ${ }^{13}$ un salario mensual acordado en paritarias y derechos laborales básicos -como vacaciones, obra social o sueldo anual complementario- no inhabilita, de ningún modo, la existencia de críticas. Las trabajadoras enfatizan también los malestares que sienten y que aquí quisiéramos señalar para dar cuenta de la pertinencia de pensar en una categoría que contemple anversos y reversos de esta relación laboral.

Hay dos aspectos que afloran con frecuencia al indagar sobre lo que genera inquietud en el trabajo: por un lado, la desvalorización y, por el otro, el maltrato de encargados/as y/o supervisores/as.

Respecto a lo primero, pudimos constatar en las observaciones de campo que existe una jerarquización o segregación espacial -completamente naturalizada- entre estas operarias y el resto de las y los trabajadores que conviven con ellas. Como sosteníamos en un texto anterior, los espacios destinados al descanso de estas mujeres están “(...) en lugares apartados, pequeños, marginales. A veces son baños que no se utilizan, otras veces son oficinas o depósitos en subsuelos, plagados de objetos y trastos en desuso (...)" (Capogrossi, 2018). Lo llamativo es que en muy pocas ocasiones surge este tema espontáneamente. Solo cuando se hacen preguntas específicas, aparecen en sus memorias algunos acontecimientos que las han marcado profundamente.

Estas experiencias reflejan la violencia que, en algunas empresas, atraviesa las relaciones: "Y (...) comíamos en el subsuelo, entre cajas, bolsas de basura. Teníamos que comer ahí porque era el único espacio que teníamos, que nos daban" (Entrevista a G, operaria de empresa de limpieza, se desempeña en oficinas de organismos públicos y en oficinas privadas, 47 años, Córdoba, 2018).

La falta de reconocimiento hacia el trabajo que realizan o hacia sus personas es otro elemento que aparece continuamente en los relatos. Esto se traduce, por ejemplo, en diferenciaciones entre las y los empleados del lugar donde se realiza el "servicio" y las operarias de la limpieza. Ellas también señalan con frecuencia la poca consideración y el desprecio que

\footnotetext{
$12 \mathrm{Al}$ realizar etnografías en otros colectivos de trabajo, como automotrices o petroleras, también notamos esta continua referencia al miedo a perder el trabajo atravesando las experiencias y las prácticas de los operarios. Casi todas las personas que entrevistamos a lo largo de nuestros veinte años dedicados a la investigación recuerdan la desocupación y los despidos de la década de 1990 como un evento traumático. En la actualidad, la profunda crisis económica, la proliferación de despidos, el incremento de la inflación y las corridas cambiarias volvieron a dar centralidad al miedo a la desocupación.

13 Estar "en blanco" supone que existe un acuerdo formal firmado entre las partes. No quiere decir, necesariamente, que las empresas respeten todas las normativas que establece el Derecho laboral, como lo demuestran los relatos de nuestras entrevistadas cuando señalan haber firmado papeles en blanco junto al contrato, al inicio de la relación laboral.
} 
demuestran hacia su trabajo las personas que transitan los lugares donde desempeñan sus tareas:

P: (...) y lo que no me gusta (...) es el maltrato psicológico, por ahí, la diferencia entre un empleado de tal lugar con el de la limpieza...

$\mathrm{E}:$ ¿Y en qué cosas les hacen notar las diferencias?

P: Y, por ahí (...) en el tema (...) de cuando desaparecen las cosas. En el tema de que por ahí no se valorice tampoco...

E: ¿Lo que una hace?

P: Claro, porque yo soy consciente de que nosotras si bien estamos para limpiar, hay gente que no... Por decirte, en un baño, ya sea de hombres o mujeres (...) el hecho de que por ahí te encontrás con... ¿viste que te escriben cosas?: que no seamos tan sucias, que limpiemos, y se olvidan de la persona que está acá...

E: ¿Les dejan mensajes a ustedes escritos en los baños?

P: Sí, sí. Así como lo ves. En X, o sea que no es que va cualquiera... son universitarios (...) Y ni hablar de las cosas que nos hacen, por ejemplo, de tirarnos las toallitas abiertas, sucias, de pegarnos en la pared. De que a lo mejor tuvo diarrea y lo dejó todo cagado al inodoro. O sea, son muchas cosas que por ahí uno dice "Sí, porque las negras de la limpieza", ¿viste?, o "las minas de la limpieza", pero vos te olvidás que (...) te sentás en un inodoro limpio gracias a mí. O sea, yo me tengo que comer los olores, yo me tengo que comer (...) que en muchas ocasiones, nosotras tiramos mucho cloro y (...) se levanta... Por ejemplo, los hombres te orinan... no orinan en el migitorio (sic) sino que te orinan en la pared... O sea, de salir descompuesta, pero tenías que limpiarlo profundamente, ¿entendés? Eso sí me molesta muchísimo. Esa desvalorización del trabajo nuestro.

E: Me decís que les escriben cosas... ¿y qué les escriben?

P: Y... te putean, porque a lo mejor está sucio...

E: ¿Y cómo saben que es para ustedes?

P: Porque te dicen "Para las negras de la limpieza", "Para las minas de la limpieza" o "Che, podrían limpiar más seguido" y se olvidan que por ahí en X, de las seis personas a lo mejor hay tres para todo $X$, ¿entendés? y tiene que salir todo. (Entrevista a $P$, operaria de empresa de limpieza, se desempeña en una institución privada y en una institución del rubro salud, 28 años, Córdoba, 2018).

E: ¿Qué es lo que más te gusta de tu trabajo y lo que odiás de tu trabajo?

F: No... de mi trabajo lo que más me gusta... no, nada [risas]. De X no me gusta nada directamente. Capaz que puede ser las compañeras y el grupo de amigas que uno va juntando ahí. Pero en general me gusta trabajar más acá, que trabajo más tranquila y se ve la limpieza que uno va haciendo (...) y sentís el olor rico o los muebles están acomodados. En cambio, en X es limpiar y limpiar y limpiar y limpiar y limpiar, y nunca vas a ver tu trabajo, como decir: "¡Guau! Mirá cómo quedó”. Capaz que estás pasando... nosotros pasamos las tablas con aserrín y un líquido. Entonces vos vas pasando y va quedando brilloso el piso y cuando ya llegaste, cuando estás terminando, te das vuelta y el piso está igual. Lo que sí odio es (...) los papelitos chiquitos, levantarlos. Eso es... [cara de sufrimiento]

E: ¿Y la gente? ¿El trato con la gente?

F: Y... tenés de todo un poco ahí. Tenés gente que es buena o... Yo, por lo general, siempre cuando tengo que trabajar pido permiso y hay gente que se molesta: "Pero 
cómo podés limpiar..."Y ahí si ya me agarra la locura y digo "A mí me mandan”. Tenés gente que vos estás limpiando y te escupe en el piso. O estás tirando la basura y tienen el tacho de basura al lado y te van a tirar la basura ahí, por donde ya pasaste: "Pero tenés el tacho de la basura al lado" y te contestan "Bueno, pero para qué estás vos".

E: ¿Por qué te molesta?

F: Porque están viendo lo que uno está trabajando (...) Pero si vos estás viendo que están limpiando al lado tuyo y vas a dejar la basura, como que me parece una falta de respeto. Para mí. Por ahí hay otras compañeras a las que no les importa nada, pero para mí sí, porque yo estoy limpiando y te ensucian y están viendo que estás transpirando y que no das más de calor y tienen el tacho de basura al lado. (Entrevista a F, operaria de limpieza, se desempeña en el rubro transporte y en una dependencia pública, 44 años. Córdoba, 2018).

El menosprecio hacia el trabajo que hacen es una característica que surge una y otra vez en los diálogos que establecemos con las mujeres empleadas en el sector y que también nos da pistas acerca de cómo el resto de las personas registran las tareas que ellas realizan. Lo que prima es la invisibilización, pese a que los y las operarias de limpieza habitan una multiplicidad de espacios por los que circulamos.

Con relación al segundo aspecto señalado en párrafos anteriores, las relaciones con las y los supervisores y/o encargadas/os de cada "servicio" están plagadas de tensiones y es en este nudo relacional donde se cuece buena parte del ejercicio disciplinar. Los cargos de supervisión se encuentran enmarcados en el Convenio Colectivo de Trabajo bajo el título "Personal de servicios de coordinación" y sus funciones son las de "(...) ordenar, organizar, distribuir y coordinar la realización de actividades". ${ }^{14}$ Estas figuras son las ejecutoras del control en el espacio laboral, son quienes encarnan la posibilidad de castigo y de maltrato. La totalidad de nuestras entrevistadas vivieron alguna situación de tensión y/o violencia hacia ellas y puede inferirse de sus relatos que las penalizaciones o las órdenes siempre quedan a libre arbitrio de quienes ofician como depositarias del mandato de los dueños/as de las empresas de limpieza en los espacios de trabajo. ${ }^{15}$

En el universo de la limpieza no doméstica asistimos al fortalecimiento de la figura clásica del capataz, típica de las relaciones salariales fordistas. ${ }^{16} \mathrm{Y}$ son ellos/as quienes definen qué tareas se hacen, cómo se hacen y cuáles son los castigos por faltar demasiado, no acatar órdenes, negarse a realizar alguna actividad o realizarla mal. En estas relaciones no existe la eufemización de la disciplina, se recurre constantemente a las suspensiones o se las traslada a lugares a donde nadie quiere ir por el ritmo o tipo de trabajo:

\footnotetext{
14 Ministerio de Trabajo de la República Argentina. Convención Colectiva de Trabajo 392. 2 de noviembre de 2004.

15 Es necesario señalar que no hay un supervisor/a por "servicio", salvo en los espacios de gran dimensión y con varios/as operarios/as. En general, aquellos/as van recorriendo diferentes lugares y controlando las actividades realizadas por los y las trabajadores/as de categorías más bajas.

16 En el convenio colectivo del sector no se habla de supervisores/as o encargados/as sino de capataces generales, capataces de primera, segunda y tercera. La diferencia entre estos últimos radica en el número de personas que tienen a cargo cada uno. Cfr. Ministerio de Trabajo de la República Argentina. Convención Colectiva de Trabajo 392. 2 de noviembre de 2004.
} 
Yo trabajé en tribunales, el que está al lado de la plaza de la... municipalidad y me trataron re mal, re mal. La supervisora de ahí cuando va gente de afuera, te hacen hacer lo que no... Lo que no trabajan los otros, te lo hacen hacer a vos y prácticamente parecés un esclavo. Porque yo estuve ahí una semana y me hicieron refregar pisos, zócalos... Horrible, porque se me lastimaron las manos, me sangraban las cutículas de los dedos tanto que nos hacían refregar y la persona que estaba ahí a cargo venía y nos pasaba el dedo para ver si estaba limpio, o cosas así y nos hacía volver a limpiar todo de vuelta. (Entrevista a L, operaria de limpieza, se desempeña en escuelas, 36 años, Córdoba, 2018).

la encargada quería que limpiáramos... era un edificio viejo, que es rentas. Y quería que limpiáramos todo lo que es zócalos, arrodilladas y con esponjas de acero. Entonces, a la otra chica la hizo que se hincara. "Hincate, híncate en el suelo y límpiame los zócalos". Entonces yo le dije que no era forma de tratar a las personas, que la época de los esclavos se había acabado hace mucho tiempo, y bueno, y ella me dijo "Después te las vas a ver...", como diciendo que me las iba a ver con ella porque ella era mi encargada y yo tenía que hacer lo que ella me dijera. Sí, yo le dije "Hago lo que sea trabajo, pero tampoco nos vas a explotar". Y esta chica, bueno, a raíz de esto, le da un golpe de tensión. Ella tenía problemas de tensión. Empieza con una hemorragia nasal $\mathrm{y}$, bueno, ella me pidió que lo llamara al marido y el marido vino, la buscó y, bueno, se quejaron de (...) esta actitud que tuvo la encarada con ella. Entonces la echaron de la empresa. (Entrevista a G, operaria de empresa de limpieza, se desempeña en oficinas de organismos públicos y en oficinas privadas, 47 años, Córdoba, 2018).

En estos espacios el ejercicio de poder no es únicamente simbólico, sino que repercute en los cuerpos porque las tareas que hacen las operarias durante cuatro, seis u ocho horas diarias implican grandes esfuerzos físicos. Las penalizaciones y castigos, en ocasiones suponen recargarlas de tareas o realizar aquellas actividades que nadie quiere hacer por lo pesadas que son, con lo cual la presión hacia estas mujeres se multiplica. En un ámbito donde las regulaciones son prácticamente inexistentes, esto se traduce en duros contextos de explotación y disciplinamiento. No queremos decir con ello que la resistencia o los espacios intersticiales donde se roba tiempo al trabajo o se caricaturizan las jerarquías no existan, pero estos problemas exceden los objetivos de este artículo y esperamos poder analizarlos en otra ocasión.

\section{Conclusiones}

La práctica etnográfica nos enfrenta a numerosos desafíos teóricos y metodológicos que implican ejercicios reflexivos destinados a repensar y revisar conceptualizaciones, estrategias y enfoques. La elección del trabajo de limpieza no doméstica como tema por estudiar, el reducido bagaje bibliográfico que existe sobre el mismo y la posición teórico-política de construir problemas de investigación atendiendo a lo que tienen para decir, discutir o problematizar las mujeres con las cuales dialogamos, nos ha posibilitado definir la categoría estabilidades de cristal. 
Creemos que ella habilita un sinnúmero de discusiones que exceden el caso aquí estudiado, una de las cuales se relaciona directamente con nuestro rol como cientistas sociales y otra con la reproducción acrítica de categorías. Respecto a lo primero, el trabajo de campo tiene la potencialidad de situarnos frente a "incidentes reveladores" (Peirano, 1995, p. 23) que nos alertan acerca de las tensiones entre los sentidos que los sujetos dan a sus experiencias y lo que observamos los y las investigadoras. Esas señales, en muchos casos son ignoradas y lo que se transmite en la literatura académica es la lectura de los/las científicos/as liberada y purificada de "interferencias". Es quizá más cómodo relajarse en los cojines teóricos conocidos que repensar los modos en que hacemos ciencia.

En el mismo sentido, optar por uno de los lados de esos binomios categoriales tan comunes a las ciencias sociales (precariedad/estabilidad; informalidad/formalidad; determinado/indeterminado, etc.), oblitera la posibilidad de crear -junto a nuestras informantes- maneras de describir y pensar sobre los lugares de trabajo, las relaciones sociales y las resistencias contemplando el carácter "polifronte" que tienen. Creemos que hay que superar estas limitaciones re-definiendo algunas categorías, y tratando de delinear conceptos que recuperen lo que nos dicen, lo que cuestionan y nos cuestionan -consciente o inconscientemente- los actores sociales con quienes construimos investigaciones.

Cuando comenzamos las pesquisas sobre el trabajo de limpieza no doméstica las tensiones nos atravesaron porque las significaciones que las mujeres daban a su trabajo confrontaban con las condiciones de trabajo que observábamos las investigadoras y con las categorías "inestabilidad", "precariedad" que bregaban por colarse en nuestros escritos. Fueron esas "incomodidades" y la imposibilidad de encontrar un término que nos resultara adecuado para dar cuenta cabalmente de este universo tan complejo, las que nos posibilitaron volver un paso atrás, recuperar lo que estaban diciendo las mujeres y redefinir nuestro esquema de análisis y nuestra posición teórica, metodológica y política.

Estas discusiones nos han permitido avanzar de algún modo en la caracterización del sector y en la descripción de algunos dispositivos disciplinares que se ponen en juego en estas empresas de limpieza tercerizadas. En ese sentido, este ejercicio etnográfico nos posibilitó aseverar que las ocupaciones en servicios de limpieza siguen siendo una de las principales opciones económicas de las mujeres que pertenecen a sectores socio-segregados de la Argentina. En general, quienes acceden a estos empleos buscan en ellos cierta formalidad laboral que no existe dentro de sus trayectorias laborales previas, las cuales están ligadas, en la mayoría de los casos, al trabajo doméstico remunerado.

Pese a la formalidad que otorgan la relación de dependencia con una empresa, la existencia de un contrato o el acceso a la seguridad social, las condiciones de trabajo se enmarcan en un halo de incertidumbre generado por innumerables derechos vulnerados. El maltrato, la rotación constante de un lugar a otro, el trabajo no pago, la imposibilidad de planificar las vacaciones, las cláusulas contractuales irregulares, entre otros, son indicadores de la precariedad que permea las relaciones laborales de las mujeres y varones que se desempeñan en estas firmas subcontratistas. 
Este escenario habilita también procesos de control y disciplinamiento extremadamente arbitrarios en algunos lugares, que no se compensan con premios o beneficios que hagan soportables las condiciones de trabajo y de vida. A diferencia de las tendencias globales de gestión en la organización de la producción y el trabajo, que se asientan cada vez más en procesos de eufemización de las relaciones de dominación; aquí asistimos a un ejercicio del poder directo, sin mediaciones y cuyo objetivo es disciplinar a través del miedo: miedo a la sanción, a la suspensión, al despido. La figura del supervisor o la supervisora es quien encarna la autoridad, la personaliza. Al convertir la disciplina en un juego têt a têt, se obliteran procesos de organización colectivos que permitan resistir a las arbitrariedades que continuamente afectan a las y los trabajadores de limpieza.

Las mujeres empleadas en estas empresas también deben soportar las representaciones sociales que se crean en torno a las tareas que realizan. Las valoraciones negativas acerca de cómo hacen la limpieza, los comentarios sobre a "servicio de quién" están y su invisibilización, -ya sea prohibiéndoles hablar o vincularse con las personas de la empresa que contrata el servicio o recluyéndolas a espacios segregados para que "no las vean"-, crean un ambiente laboral marcado por las segregaciones y las jerarquizaciones. Es nuestra intención profundizar estos aspectos en los próximos trabajos y poder contribuir con ello a la problematización de los estudios donde el género y la clase se interrelacionan.

Para finalizar, no queremos dejar de señalar que las operarias de limpieza son sometidas a una doble $-\mathrm{y}$ a veces triple- jornada de trabajo, aquella que se desarrolla bajo relaciones salariales y aquella que es producto de los roles de género asignados socialmente y que supone que la esfera de la reproducción es "responsabilidad natural" de la mujer. Esta dimensión es fundamental para comprender el endurecimiento de las condiciones de vida de las mujeres de los sectores que acceden a estos nichos laborales del mercado de trabajo.

\section{Referencias}

Basualdo, V., y Esponda, A. (2003). Aportes sobre la presencia e impacto de la tercerización en la Argentina actual (pp. 21-66). En M. V. Basualdo; A. Esponda; G. Gianibelli y D. Morales (comp.), Tercerización y derechos laborales en la Argentina. Buenos Aires: La Página.

Battistini, O. R. (2018). ¿Qué hay de nuevo y de viejo en la subcontratación laboral moderna? Sociológica, Año 33, 93, 281-318.

Capogrossi, M.L. (2020). Les falta el látigo para que seamos esclavos: aproximaciones a las condiciones de trabajo de las mujeres en empresas de limpieza no doméstica en Argentina. Íconos, Revista de Ciencias Sociales, 66, 173-190. DOI: https://doi.org/10.17141/iconos.66.2020.3753

Capogrossi M. L. (2018). C'est mieux s'ils ne te voient pas. Les conditions de travail des femmes dans les entreprises de nettoyage de la ville de Córdoba (Argentine). Ponencia presentada en las Journée d'études Argentine/France «Enquêter sur les transformationes et les crises du travail: regards croisés France - Argentine», organizadas por el Centre de Recherches Sociologiques et Politiques de París - CNRS 
- Université Paris 8, Saint Denis, Univerité Paris Ouest Nanterre y por el Laboratoire interdisciplinaire pour la sociologie économique, CNAM. París, 12 de noviembre de 2018.

Carrasco, C. (1999). La sostenibilidad de la vida humana, ¿un asunto de mujeres?. Mientras tanto, 83,1-29.

De la Garza, E. (2012). La subcontratación y la acumulación del capital en el nivel global. En: J. C. Celis Espina (comp.), La subcontratación laboral en América Latina: miradas multidimensionales (pp. 15-37). Medellín, Colombia: Escuela Nacional Sindical.

Dresch, G. A.; Vieira Zanardine, L. R., y Faux, S. (2015). As trabalhadoras da limpeza de uma instituição pública de ensino superior: gênero, tercerização e precarização. Revista Vernáculo, 36, 106-136.

Entwistle, G. (2015). Politicas de limpieza. Trayectorias laborales, desigualdades múltiples y movilidad social entre las mujeres del servicio de limpieza de calles en Cochabamba, Bolivia. Buenos Aires: CLACSO. Documento de trabajo.

Franco Quiñónez, R. C., y Santacruz Ortiz, E. (2016). El trabajo tercerizado y su impacto en la salud de las trabajadoras de limpieza: perspectiva y experiencia, en los años 2015 2016. Paraguay: Instituto de Trabajo Social. UNA.

Gorban, D., y Tizziani, A. (2018). Las ocupaciones en los servicios de limpieza y de estética: algunas pistas para reflexionar en torno de la movilidad laboral de las mujeres de sectores populares en Argentina. Revista Internacional de Organizaciones, 20, 81-102.

Goren, N. (2017). Desigualdades socio-laborales. Una aproximación a sus marcos interpretativos desde la perspectiva feminista. Revista Latinoamericana de Antropología del Trabajo, 2 (2), 1-21.

Kruger, M.; Pérez Nebra, A. R., y Antloga, C. S. (2016). Relação entre significado do trabalho e rotatividade de serventes de limpeza. Psicologia: Organizações e Trabalho, (16) 2 , 90-202.

Leite Lopes, J. S. (2011). El vapor del diablo. El trabajo de los obreros del azúcar. Buenos Aires: Antropofagia.

Levi-Strauss, C. (1988). Tristes Trópicos. Barcelona: Paidós.

Ley 20744. Cfr. Régimen de Contrato de Trabajo. Sancionada el 11 de septiembre de 1974 y modificada el 5 de mayo de 1976. Recuperado de: http://servicios.infoleg.gob.ar/infolegInternet/anexos/25000-29999/25552/texact.htm

Longo, M. E. (2011). Heterogeneidad de trayectorias laborales y temporalidades juveniles. Cuestiones de sociología, 7, 54-77.

Lorey, I. (2016). Estado de inseguridad. Gobernar la precariedad. Madrid: Traficante de sueños.

Magliano, M. J. (2017). Las trabajadoras invisibles: experiencias laborales de mujeres migrantes en Argentina. Revista Latinoamericana de Antropología del Trabajo, 1 (1), $1-23$.

Mallimaci, A., y Magliano, M.J. (2016). Migraciones, género y cuidados en Argentina: jerarquizaciones, desigualdades y movilidades (pp. 83-110). En: M.J. Magliano; M. V. Perissinotti y D. Zenklusen (comps.) Los nudos ciegos de la desigualdad. Diálogos entre migraciones y cuidado. Buenos Aires: CONICET.

Muñiz Terra, L.; Roberti, E.; Deleo, C., y Hasicic, C. (2013). Trayectorias laborales en Argentina: una revisión de estudios cualitativos sobre mujeres y jóvenes. Revista Lavboratorio, Año 14, 25, 57-79. 
Palomino, H. (2003). Pobreza y desempleo en la Argentina. Problemática de una nueva configuración social. Buenos Aires: CESPA.

Peirano, M. (2004). A favor da etnografía. Río de Janeiro, Brasil: Relume Dumará.

Pérez Orozco, A. (2014). Subversión feminista de la economía. Aportes para un debate sobre el conflicto capital-vida. Madrid: Traficante de Sueños.

Rockwell, E. (2009). La experiencia etnográfica: historia y cultura en los procesos educativos. Buenos Aires: Paidós.

Skeggs, B. (2019). Mujeres respetables. Clase y género en los sectores populares. Los Polvorines. Buenos Aires: Universidad Nacional de General Sarmiento.

Soul, J. (2015). Somiseros. La configuración y el devenir de un grupo obrero desde una perspectiva antropológica. Rosario: Protohistoria Ediciones.

Tizziani, A. (2017): Las ocupaciones de limpieza en la ciudad de Buenos Aires: territorios y significados en torno al «trabajo femenino» y el «trabajo masculino». Ponencia presentada en el Seminário Internacional Fazendo Gênero (Anais Eletrônicos), Florianópolis. Recuperado de:

http://www.en.wwc2017.eventos.dype.com.br/resources/anais/1499448503_ARQUIV O_PonenciaAniaTizziani.pdf 